\title{
Rationalization of gathering information about passenger traffic on routes
}

\author{
Iosif Spirin $^{1 *}$, Vladimir Sarbaev ${ }^{2}$, and Vitaliy Bugrimov ${ }^{2}$ \\ ${ }^{1}$ Joint-Stock Company «Scientific and Research Institute of Motor Transport», 125480 Moscow, \\ Russia \\ ${ }^{2}$ Moscow Polytechnic University, 107023 Moscow, Russia
}

\begin{abstract}
Meeting the challenges of implementing sustainable transport planning and technological organization of transportations requires knowledge of information about the demand for travel. This information is not collected to current statistical accounting system. This article examines matters relating to the application of information technology to obtain the inter-district transport correspondences and data about the needs of passengers to travel on existing routes. The article provides an analysis of the methods of reducing the volume of correspondences of transport surveys on the routes. Purpose of the article - Using these methods allows you to reduce the costs of monitoring information about passenger traffic.
\end{abstract}

\section{Introduction}

At present in Russia, based on the experience of developed countries, integrated transport planning is beginning to be applied, which in the world practice has been named Sustainable Transport Planning (STP). Recent studies of Persia [1], Cohen-Blankshtain [2], Miller [3], Spirin [4] as well as earlier works by the authors May [5], Lowson [6], and many others have shown that STP has become the global focus of the implementation of transport policies. Sustainable transport planning is used to develop transport systems in a complex with the solution of population mobility problems, development of settlements, land use, resettlement of inhabitants, preservation of the environment, transport infrastructure development, increase of attractiveness of urban passenger transport (UPT). For the first time, the concept of sustainable transport planning and its components were identified and considered at international conferences under the aegis of the United Nations [7, 8].

Sustainable transport planning in the EU is considered in detail in May's study $[5,9]$. One of the main directions of sustainable development cities and their transport systems is the improvement of UPT. It is recognized that to counteract rampant automobilization of the population can only be offered an alternative - a more convenient and economical UPT.

Implementation of sustainable transport planning and technological organization of transportations of UPT need information basis. The most laborious and expensive in obtaining information is the data on passenger traffic. Passenger traffics dynamically change in accordance with the development of the urban environment, demographic processes and

* Corresponding author: ivspirin@yandex.ru 
socio-economic conditions. The cost of obtaining data on passenger traffic exceeds $95 \%$ of the total cost of collecting the initial information used to solve the planning and organization of transport, which is investigated in the Spirin's work [10]. The system of statistical observation operating in Russia does not include data on passenger traffics, and their monitoring is not carried out.

\section{Material and methods}

The methodology of research and development includes modeling of passenger traffic on routes, the analysis and adaptation of the experience in the areas of technologies of passenger transportation on urban and suburban transport routes, information support of these transportation, planning passenger transport in smart cities, theories of engineering experiment and inaccuracies. In order to analyze the state of the investigated problem, modern scientific publications of Russian and foreign scientists were used.

The requirement of passengers in transport movements for the purpose of developing the UPT route network is represented by inter-district correspondence - the number of passengers following the period under consideration between each pair of transport areas, as described in the Moon's studies [11]. Interregional correspondence can be taken into account on the basis of counting the number of relevant network trips made from the beginning of the trip to its end. Traditionally used methods of studying passenger traffic in cities are considered in Zengbush's work [12]. This book also shows the use of information received on passenger traffics to improve the work of UPT.

At present, due to the development of information technologies (cellular telephony, navigation and satellite equipment, etc.), it is technically possible to obtain inter-district transport correspondences without special surveys. Certain difficulties represent the separation of network mobility between: (a) UPT; (b) driving in passenger cars; (c) on bicycles; (d) by walking. This can be done by analyzing the actual speed of movement of people. Solving the problems of technological organization of transport on UPT routes (the composition of tasks is considered in detail in Spirin's research [13]) use the following information (starting with general information and ending with the most detailed information, according to a study by Spirin [13]):

- the volume of traffic - the number of trips made. Knowledge of the volume of transport does not allow solving most problems of technological organization of transportations, since such information is not tied to the time and place of landing and disembarkation of passengers;

- passenger traffic on all sections of the route and time of day - shows the filling of vehicles by passengers on different sections of the route. Such information is also not enough for solving the whole complex of tasks of organizing transportation;

- information on the number of passengers who have boarded vehicles and left them at different stopping points in each of the traffic directions and at certain times of the day (passenger entrances and exits). Information on inputs and outputs can be obtained automatically;

- transport correspondence between each pair of stop points (bus stop station) - the number of passengers traveling between each pair of stopping points of the route. This is the most detailed type of information. Correspondence is not amenable to automated accounting.

Algorithms for solving all problems of technological organization of transportations on routes have been developed, using only information on entrances and exits (that is, requiring no knowledge of correspondence). This significantly simplified the formation of an information basis necessary for solving the problems of technological organization of transport, without deteriorating the quality of the solution of problems, as described in the study of Spirin [13]. 
Obtaining information about the needs of passengers on trips is possible with the use of modern information technology. Passenger's smart cards and tickets for one trip can be equipped with RFID tags (transponders). These labels can be read by scanners when boarding and disembarking from the vehicle. The GPS / GLONASS system provides information about the landing and landing area. It should be ensured that the information received is impersonal and human rights are not violated.

To automatically determine the number of passengers entering and exiting the vehicle at each stopping point using various technical means. In the work of Yenin [14] provides a detailed review and analysis of the use of such technical means.

To mechanize surveys of passenger traffics produced manually, clickers are used. Clicker has a button, when clicked on, the counter reading is incremented by one.

The automatic registrars of passenger traffic are equipped with various contact or proximity sensors that identify the presence of a passenger. The most common contact sensors are: (a) pressure type "step"; (b) by weight; (c) the validator. The sensor "step" is installed on top of the steps of the vehicle doors. A set of weight sensors (more correctly speaking - mass) responds to the total sprung mass of the vehicle. Such sensors are equipped with each wheel. The number of passengers is determined based on the average body weight of a person - approximately $70 \mathrm{~kg}$. The validator reacts to smart cards and other electronic tickets, opening access to the vehicle's interior.

Validators are often used in "electronic conductor" systems. The first such system in Russia was the Automated Fare Control System - ASCP, implemented on the routes of UPT Moscow, as shown by the Ismailov's research [15]. The passenger must attach his smart card or another electronic ticket to the reader. After that, the passenger can pass into the vehicle salon. For carriers, the use of a validator provides for an increase in the collection of a fare. At the same time, the validator takes into account the number of incoming passengers. Accounting is conducted separately for different categories of passengers: (a) ordinary passengers; (b) disabled persons who are exempt from travel; (c) students paying for social fare. In Russian cities, tariffs are used that are independent of the distance traveled by a passenger. Therefore, at the exit of passengers from the vehicle, the validators are not installed. This does not allow you to get information about the number of passengers who left. It is necessary to equip all the passenger doors with validators in order to have complete information on the entry and exit of passengers. The real purpose of the validator is not to collect the fare (which is of interest only to the carrier), but to provide basic information for the organization of transportation and the development of sustainable transport planning (the interest of consumers of services - passengers and the whole society).

Non-contact sensors operate on different principles: (a) the intersection of passengers with an infrared ray or visible light beam; (b) video registration or photographic registration; (c) combined sensors sensitive to different signals.

Main characteristics of sensors and instruments summarizing their indications are: (a) the price and unit cost per registration of a certain number of passengers over the useful life; (b) data error. The error of various sensors according to Yenin's research [14] is in the range from $5 \%$ to $50 \%$. During rush hours because passengers enter, the traffic of passengers entering the passenger compartment is very tight.

\section{Theoretical substantiation of rationalization of information on passenger traffic on routes (Research and development)}

It should be pointed out that the error automatic counting the number of passengers is systematic. The true number of passengers is greater than that shown by the sensors. After the experimental verification and calibration of the sensors, the established systematic error can be taken into account. As a result, the error can be reduced to an acceptable level of $3 \ldots$ 
8\%. Examination of correspondence on routes requires the use of numerous number of employees. A method is proposed for reducing the volume of a survey of inter-set correspondence with the participation of people, as described in the study of Spirin [13]. Part of the correspondence is proposed to be determined by interviewing passengers at the stopping points. Another part of the correspondence can be determined by calculation. For this, three groups of equations can be used:

$$
\begin{aligned}
U_{i} & =\sum_{j>i} K_{i j}\left(\text { just have }\left(n_{0}-1\right) \text { these equations }\right) \\
B_{j} & =\sum_{i<j} K_{i j}\left(\text { just have }\left(n_{0}-1\right)\right. \text { these equations) } \\
H_{i} & =\sum_{m \leq i} \sum_{n>i} K_{n m}\left(\text { just have }\left(n_{0}-1\right) \text { these equations }\right)
\end{aligned}
$$

where $U_{i}$ - the number of passengers who started the trip at the stopping point $i$ (landing), passengers (pass .); $B_{J}-$ the number of passengers who completed the trip at stopping point $j$ (disembarkation), pass .; $H_{i}$ - the number of passengers in vehicles passing through the route that starts from the stopping point $i$ (vehicle filling passengers), pass.; $K_{m n}-$ correspondence between the stopping points $m$ and $n$, pass .; $n_{0}-$ is the number of stopping points on the route in the considered direction of movement, units.

$U_{i}, B_{j}$ and $H_{i}$ parameters, those appear in formulas (1), (2) and (3) are interrelated. Any two of them are independent, and the third is determined by the calculation. Therefore, you can use only two of the three equations (for example, the first and second equations). In total, you can use $2\left(n_{0}-1\right)$ equations, from which you can calculate the same number of correspondence. The rest of the correspondence should be determined on the basis of the survey.

The total number of correspondence between the stopping points of the route is $n_{0}\left(n_{0}-\right.$ 1)/2. Let information about the entrances and exits of passengers be known. Then the number of the correspondent correspondence for $n_{0} \geq 4$, minus calculated by the formulas, is equal to $\left(n_{0}-1\right) \cdot\left(n_{0}-4\right) / 2$. If the route has 4 stops or less, all correspondence can be determined by calculation. With an increase in the number of stopping points, the proportion of correspondence that can be determined by calculation is reduced (Fig. 1). For average operating conditions, the number of stops on the route does not exceed 13 units. Therefore, usually by calculation, you can get more than $30 \%$ of correspondence, which reduces the cost of examination.

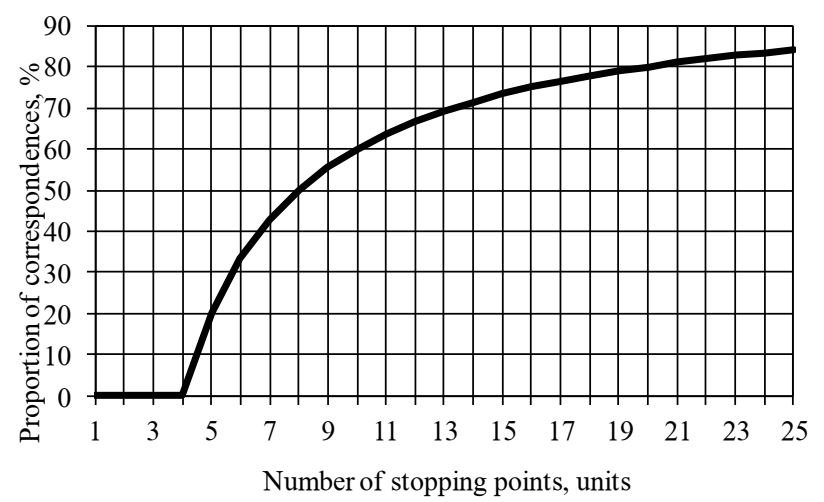

Fig. 1. Dependence of the proportion of correspondence that will need to be surveyed, from the number of stop points on the route. 
Necessary accuracy of information on passenger traffics is determined by the fact that there are two possible options for influencing this information on the calculation results: (a) it is necessary to increase the number of vehicles operating on the route; (b) the number of vehicles should be reduced. In other words, in the extreme case, the change in the number of vehicles is \pm 1 unit. It should also be noted that on every fourth bus route in Russia there are $1 \ldots 4$ buses only.

In any case, the absolute error value is \pm 0.5 units of the rolling stock, since the number of rolling stock units must be rounded to an integer. In Spirin's work [13] it is shown that practically sufficient error can be more than $5 \%$ depending on the number of vehicles operating on the route (Fig. 2).

For solving the problems of long-range transport planning, passenger correspondence can be determined on the basis of modeling. Has spread probabilistic model was based on the following mathematical dependencies:

$$
X_{12}=B_{2} ; \quad X_{i j}=B_{j} C_{i j} / H_{j-1}
$$

where $C_{i j}$ - the number of passengers who have boarded the vehicles at the stopping point with the number $i$, and left at the stopping points with the numbers $j$ and all subsequent passages; $H_{j-1}-$ filling of vehicles by passengers on the route segment between stopping points with numbers $(j-1)$ and $j$, pass.

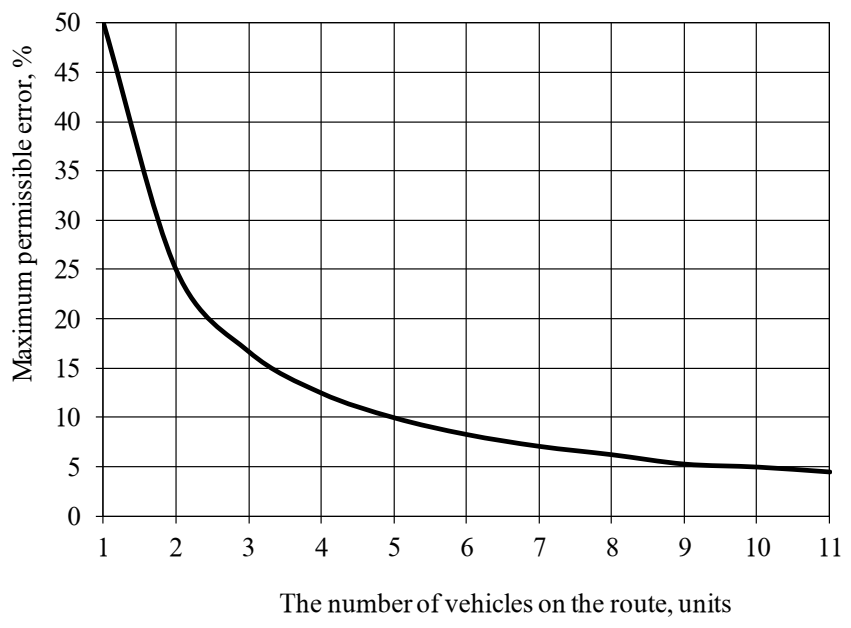

Fig. 2. Dependence of the maximum permissible error of information on passenger traffic from the number of vehicles on the route.

It is also necessary to take into account that

$$
C_{i(i+1)}=n_{i} ; C_{i j}=C_{i(j-1)}-K_{i(j-1)}
$$

where $n_{i}$ - the number of passengers traveling along the route segment starting from the stop point with the number $i$ to the next stop point, pass.

\section{Results and discussion}

The methods proposed in this article for streamlining information on passenger traffic reduce the scope of work and the cost of obtaining the necessary data for transport planning and the development of timetables for urban transport. 
Practical use of the considered developments is carried out: (a) in passenger traffic monitoring systems on urban transport routes; (b) in developing plans for the sustainable development of the urban transport system; (c) for the development of timetables for urban public transport.

Considered methods of improving the work on the definition of passenger traffic are discussed in detail in the different manual for example in Moon's study [11], which contains recommendations for practical:

- to organize and prepare a survey of passenger transport;

- the choice of facilities, methods and timing of surveys;

- identifying the necessary labor, material and financial resources;

- the methodology for calculating the size of a representative sample;

- the procedure for recording the number of passengers carried by different methods;

- calculation of the normative indicators of the transport mobility of the population of different social categories;

- the methodology for the statistical assessment of the volume of passenger traffic and passenger turnover;

- recommendations for the organization and conduct of statistical surveys and the processing of the resulting materials.

\section{Conclusion}

The methods of improving the reception and monitoring of data on passenger traffics examined in the article make it possible to significantly reduce the labor intensity of performing transport surveys and reduce the costs of these surveys. The use of these methods ensures that calculations are carried out when developing plans for the sustainable development of urban transport systems. The implementation of developments in the practice of transport organizations provides an improvement in the quality of passenger transport services according to Azaliev's research [16]. On this basis, the quality of life in cities with more than $70 \%$ of citizens can be improved.

\section{References}

1. L Persia, E Cipriani, V Sgarra and E Meta, Strategies and measures for sustainable urban transport systems, Transportation Research Procedia: 6th Transport Research Arena (TRA) Warsaw Poland, vol. 14, p. 955-964 (2016)

2. G Cohen-Blankshtain and O Rotem-Mindali, Key research themes on ICT and sustainable urban mobility, International Journal of Sustainable Transportation, 10 (1), p. 9-17 (2016)

3. P Miller, A G de Barros, L Kattan and S C Wirasinghe, Analyzing the sustainability performance of public transit, Transportation Research Part D - Transport and Environment, 44, p. 177-198 (2016)

4. I Spirin, D Zavyalov, N Zavyalova, Globalization and Development of Sustainable Public Transport System,s $16^{\text {th }}$ Int. Scientific Conf. Globalization and Its SocioEconomic Consequences. University of Zilina (Slovakia). The Faculty of Operation and Economics of Transport and Communication, Department of Economics. Procedia, Part V. $5^{\text {th }}-6^{\text {th }}$ October 2016, pp. $2076-2084$ (2016)

5. A May, S Shepherd and P Timms, Optimal transport strategies for European cities, Transportation, 27 (3), pp. 285-315 (2000) 
6. M Lowson, New Approach to Effective and Sustainable Urban Transport, Transportation Research Record, 1838, p. 42-49 (2003)

7. United Nations Conference on Environment \& Development Rio de Janeiro. Available: https://docs.google.com/gview?url=http://sustainabledevelopment.un.org/content/ddoc ument/Agenda21.pdf\&embedded=true, 2011

8. United Nations Conference on Environment \& Development Rio de Janeiro. Available: http://rio20.net/wp-content/uploads/2012/06/N1238164.pdf.

9. A May, Urban transport and sustainability: The key challenges, International Journal of Sustainable Transportation, 7 (3), p. 170-185 (2013)

10. I V Spirin, Transportation of passengers by public transpor, reference book Moscow: Publishing and bookselling center "Akademkniga", p. 413 (2003)

11. E E Moon, E S Moskvichev, I V Spirin and A S Faizulin, A guide to the regulation of mobility passengers urban transport: a manual for transport workers and bodies of State statistics. Moscow: Publishing and bookselling firm "Catalogue", p. 128 (2005)

12. M V Zengbush, A Yu Belinskii and A G Dynkin, Passenger traffic in the cities Moscow. Publishing House «Transport», p. 136 (1974)

13. I V Spirin, The scientific basis for a comprehensive restructuring of urban passenger transport, Monography Moscow. Publishing and bookselling firm "Catalogue", p. 222 (2005)

14. D V Yenin, Analysis of passenger traffic Monitoring automated systems, The Bulletin of Road Transport Research, 6, p. 12-22 (2013)

15. R I Ismailov, V A Maksimov, A V Postolit, A A Emel'yanov and A V Mikhaylov, Operation of the automated control system of travel in terms of bus companies of "Mosgortrans", Moscow. MADI (State Transport University), p. 254 (2007)

16. A M Asaliev, N B Zavyalova, O V Saginova, I V Spirin, I I Skorobogatykh et al., Marketing approach to quality management of transport services, Monography Novosibirsk. Publishing House CRNS, p. 172 (2016) 